Western Energy Policy: The Case for Competition. By D. Evans. Pp. 198. (Macmillan: London, 1979.) £10.

THE title might suggest at least a stimulating polemic. Western energy policy, if it can be said to exist as an entity, is a mess. Uneconomic coal production competes for a scarcely growing electricity market with increasingly questioned nuclear power; both, in consequence, find themselves needing to be subsidised. Oil prices are set by the mood of the OPEC cartel rather than production costs. Natural gas, priced far below its replacement costs, threatens to drive its competitors, and possible successors, out of the dom sstic and prime industrial markets. Policy is an improvised assembly of measures to deal with an inheritance of inertia, legislation, established interests, and social constraints rather than a strategy deliberately designed to take industrial society through its shortterm difficulties on to a path to an attainable and tolerable future.

At such times the clarity of the classical market theory becomes irresistibly appealing to those who feel that even complicated questions should have simple answers. Douglas Evans is one who believes that "it has been one of the sadder features of the post-war British economy to be more concerned with the distribution of income rather than the utilisation of resources", a condition brought about by governments which have "eroded the characteristic qualities of free competition". His work "makes no secret of its belief in the virtues of a free enterprise framework".

The book, however, totally fails to make any coherent case for a free market in energy. In fact, it is, in the end, difficult to know what case is being made at all. It provides a brief and superficial survey of past energy trends in the EEC countries, Japan, the US, and even makes a brief nod in the direction of China. There follows a look at some of the present energy policies, and objectives, of the UK, Germany, and the US. The vicissitudes of President Carter's energy proposals, which have still not reached an end, are described at length. One must sympathise with anyone trying to draw all the activity-and non-activity-in energy policy making in the Western nations into a comerent pattern: it is a very difficult task. But because it does not provide a clearly defined viewpoint or establish a coherent set of evaluative criteria-apart from stating a few truisms such as the desirability of using energy more efficiently, and the need to ensure policies are humane and effective-Mr Evans' analysis is far more in the tradition of anecdotal newspaper journalism than a serious critique of policy. Having read it one is somewhat better informed on contemporary energy matters but is still left without any real feel for the strength of the forces at work or for the magnitude and nature of the problems to be solved.

There are also errors and misspellings about which one should not become pedantic; nevertheless, they have an undermining effect. Liquefied natural gas is not the same as synthetic natural gas (SNG). Britain does not export 40 million tons of coal now to the EEC, or anywhere else. The size of power stations is usually given in megawatts -not milowatts. And surely it is not true that "because they invariably entail an extended and often complex process of decentralisation, conservation policies take some years to prove their effectiveness, that is, their lead times are long-to use the jargon of energy planners". There is a mountain of evidence to the contrary. Simple and inexpensive conservation measures such as draught-stripping, pipe-lagging, improved maintenance of boiler systems, cavity wall insulation and installation of control systems, can provide almost instant and, at times, quite dramatic savings in energy consumption.

This is not a book completely without merit. It pu's together a lot of information about energy policy in the Western industrial world; it shows, by that alone, how much work needs to be done. And Evans is often shrewd and perceptive in his comments. But the book he has written does nothing to make a case for founding future policies on increasing competition between energy suppliers. Neither does it offer any guidance to what might be done instead.

Gerald Foley is a Fellow of the International Institute for Environment and Development (IIED), London, UK.

\title{
Drops, bubbles and solid particles
}

Bubbles, Drops, and Particles. By R. Clift, J. R. Grace and M. E. Weber. Pp. 380. (Academic: New York, San Francisco and London, 1978.) \$32; $£ 20.80$.

THE literature on the hydrodynamics of drops, bubbles and solid particles is notorious for the enormous range of journals in which important contributions appear. Thus, a book which attains the author's objective of presenting a "comprehensive, critical review of the literature" would be of great value.

In the area in which this reviewer has specialised knowledge, few references are omitted so that the claim to be comprehensive can be supported. The reader can thus work his way into the literature of a particular problem aided by a clear summary of the principal papers he needs to read. This in itself would make the book worthwhile. However, a work of length many times the 380 pages at the authors' disposal would be required for a really deep critical account, so the authors' second claim is perhaps less justified. Nevertheless, the text is, considering the vast amount of information it carries, readable, and it manages to point up areas where more work is needed. In discussing the effect of surfactants on bubble drag at large Reynolds numbers ( $p$ 135), for example, the authors note that "accurate experimental data with known surfactant concentrations do not appear to be available" and "the conditions which must be satisfied for the theories to hold are so stringent that [the] theories are of little practical importance"; a challenge to both experimenters and theoreticians.

The organisation of the book is excellent. It was an inspired thought to place the numbers of the chapters in which various shape regimes are studied on a Reynolds number versus Eotvos number diagram, so that the plan of the work can be absorbed at a glance. In 